\title{
Study on the Investment Function of Family Library*
}

\author{
Tiechen Qi \\ Huali College Guangdong University of Technology \\ Guangzhou, China 511325
}

\begin{abstract}
This paper analyzes the features and functions of family library, and points out that family library can promote people's interest in domestic libraries by excavating its investment function. After that it enriches family collection and promotes the nationwide reading.
\end{abstract}

\section{Keywords-family library; nationwide reading; investment}

\section{INTRODUCTION}

The family library originates from the study and library of ancient Chinese scholars. After several thousand years of development, this concept was widely advocated by public opinion during the period of republic of china. In today's prosperous socialist culture, family library plays an irreplaceable role in spiritual civilization construction and socialist modernization. Exploring the investment function of family library can enrich its connotation, and at the same time, it can also encourage and guide people to carry out various reading activities centering on family library and promote the reading of the whole people.

\section{A. The Definition of the Family Library}

Because social popularity is narrower and the low degree of family recognition, the family library only existed in a small number of families. In theoretical research, only a few scholars pay attention to the development of family library. The author takes "family library" as the retrieval term and the subject as the retrieval item to carry on the retrieval in the China knowledge network literature database, and the retrieval consequence are 218 records.

At present, the field of Domestic Library Science has not formed the unified understanding to the family library, and the family library has not the authoritative definition. According to Qiao Yang, "What this [1] refers to a family library that collects books and periodicals and provides public use within a certain range". Wang Hui [2] thinks that "Community family library refers to the government guidance, in a planned way for residents to the voluntary participation, with volunteers family study is given priority to, government funding is complementary, set up the mechanism of exchange, book Shared network, for the community to the general public or to a range of special groups provide mass reading or professional reading of pure small convenient public library". In addition, there is also the view [3] that the database of electronic books established by

*Fund project: this paper is the final result of "family library", 2016 provincial university students innovation and entrepreneurship training program project of Guangdong province, project number: 201613656016

\author{
Shuangmei Chen \\ Huali College Guangdong University of Technology \\ Guangzhou, China 511325
}

individual families using modern information technology is also called the family library.

Compared with the concept of traditional library, the author believes that family library is a new type of the service of document resource that has the function of library collection, and provides borrowing service in a small range with family as the unit, not for the purpose of making profits.

\section{B. The Basic Features of the Family Library}

Compared with the tradition entity library, the family library has very obvious characteristics: one is non-profit. The family library is not an enterprise unit, the purpose of which is to satisfy one's own cultural needs and provide others with some resources of literature of convenient help. However, it should be pointed out that the investment function of the family library proposed in this paper is not inconsistent with its non-profit function. Second, the collection of books to paper books, supplemented by a small number of electronic books. Family library is built on the foundation of family study commonly, and there is certain equipment of collect books, still store all sorts of electronic books on domestic computer at the same time. Third, family use is the main, and sharing features is not obvious. The family library appears on the basis of the family, taking the family as the carrier. The family's emphasis on privacy means that the family library is usually not shared with others. Fourth, the family library is voluntary construction and independent investment. Family libraries mainly meet their own needs, and the funds needed in the construction process are borne by families themselves. In some cases, government departments may give some rewards of spirit and material support to family libraries with remarkable effects. Fifth, is not professional. The management personnel of the family library is family member, and they generally do not have professional knowledge of library management.

\section{Functions of Family Library}

The function of family library can be divided into basic function and derivative function. The basic functions of family library refer to the basic functions of the traditional physical library such as collections, readings, borrowings, promotions and learning. The derivative function of family library refers to the additional non-basic functions formed by the influence of family atmosphere on the basis of its basic functions, such as decoration, social contact, education, community management, family cultural inheritance, investment, etc. 
At present, the existing among the various types of family library, its basic function is very obvious already, such as family advocated in ShenZhen LuoHu district library [4] construction, JiangSu JingJiang community Ju Feng family library "reserves" [5], QingPu, Shanghai library "family library seed program" [6], "family library system" put forward by the ChongQing YuBei district library [7], the cultural department of Shaanxi province 1000 family library program, etc. However, the derivative function of family library is not obvious at present, and it is not uniform. Some families build a family library for their children education, some to meet the need to improve their own cultural accomplishment, and some also underline the cultural characteristics of the family.

This paper discusses the investment function of family library. At present, almost all kinds of books do not have the investment function (mainly from the perspective of business). However, the author finds that the family library not only has the property of business investment, but also has a certain investment function.

\section{INVESTMENT DIRECTIONS OF FAMILY LIBRARY}

The investment property and investment function of family library are reflected through specific behavior of investment. Only when the investment direction of family library is found correctly can the value of its investment be seen and the family (investor) be given greater confidence and return.

In general, the author thinks that the investment function of family library can be reflected in the following five aspects:

\section{A. The Author's Autographed Books}

Author autograph book refers to the author's signature, signature, seal, etc. in the work, and sometimes writes down a brief expression of emotion. In addition, some famous books may contain celebrity books, inscriptions, etc. There is nothing special about a book among the many copies, but once the author's autograph, or the collection of famous books, inscriptions, etc., the value of a book is greatly different. The UK's concise Britannica entry on the value of editions also states: "The best collection of books is those which have the signature or inscription of the author, or which are possessed, used and stamped by celebrities". In the world of collecting, there are books with celebrity signatures and messages on the title page, and there is a saying that "once a subject is worth a lot". At present, signature book has become an investment object, and many collectors in the society are doing business of signing books while improving their own cultural accomplishment through reading. Having a family library can also provide a certain amount of financial return, which is a good choice for families facing enormous economic pressure.

\section{B. The Wool-edged Books}

The wool-edged book is the book that has been printed and bound without cutting off the light, "three sides of the book as it is, without cutting knife", the page is connected to the page, the reader needs to read it with tools cut. In addition, in the book "heaven", "earth" and around, leaving more blanks, is an interesting way of binding. In fact, as the final process of the unfinished "semi-finished", the book will appear a jagged fold, and its content is no different from other general books. The reason why the wool-edged books attract people's attention is its rarity. In general, the publishing society sets aside about 200 volumes of books to make rough copies each time they are printed, which only meets the special needs of a few readers. The family library has a very obvious nature of personal collection, if a certain number of Frontier books can be collected, for the collector is really a lot of special assets.

\section{Early Books by Famous People}

The authors of some books (writers, entertainers, politicians, etc.) are less well known before they become famous, and their works are generally not well received. But as soon as these authors become famous, their works will attract more attention as their personal influence explodes. People not only pay attention to the author's latest works, but also use all the clues to find some of his early books. For example, comrade Wang Huning was elected to the political bureau of the CPC central committee at the first plenary session of the 19th CPC central committee in October 2017. Then, on the second-hand book market, some works published by comrade Wang Huning in the 1970s and 1980s were sold for exorbitant prices. According to kongfu's old book website (http://www.kongfz.com/, nov 11, 2017), Wang Huning Set -- Comparison - Beyond is priced at 8,888 yuan (priced at 3.5 yuan, 1989), and the complete set of Open Series to which the book belongs is also priced at 9,999 yuan; Administrative Ecological Analysis is priced at 3,200 yuan.

Therefore, collectors of family libraries can pay close attention to some "diamonds in the rough" in the fields of art, politics and entertainment, and collect their early works in order to get some economic returns when the authors become famous. Of course, choosing this investment along proper lines requires a certain vision and judgment of the household library's furniture collection.

\section{Out-of-print Books}

Out of print books refer to books and other cultural products, for some reason, no longer published. When a book is out of print, it means it will never be published again, so the remaining editions are especially valuable.

Cultural Perplexity in Agonized Travel is the opening work of Mr. Yu Qiuyu. It is a classic work of cultural prose that has been selling well for many years. The book was first published in 1992. In the past 25 years, in the process of repeated editions, Mr. Yu Qiuyu revised and rewritten this work a lot. In October 2017, Mr. Yu Qiuyu personally revised and added illustrations to Cultural Perplexity in Agonized Travel. This edition is the result of Yu Qiuyu's verbatim revision and new addition to the old edition of Cultural Perplexity in Agonized Travel, and is also the final edition of Cultural Perplexity in Agonized Travel. 
It would be a great honor for the family library to have "one edition, one print" (the first edition, the first printing) and the last edition. What's more, there are collectors who collect all the versions of Cultural Perplexity in Agonized Travel. Because, at this time of Cultural Perplexity in Agonized Travel for readers and collectors, is both spiritual and material wealth.

\section{E. Award-winning Books}

Award-winning books refer to books that have been reviewed by authoritative bodies and awarded honorary titles, such as "the most beautiful book in the world", "the most beautiful book in China", "the prize for contradictory literature" and the Nobel Prize for literature. Once the prize is won, the book will receive wider attention. In February 2018, the 2008 "World's Most Beautiful Book" award was announced in Leipzig, Germany. The two works Annotation of Yuanye and Tea Book was awarded silver award and honorary awards respectively by the Shanghai Press and Publishing Bureau and the "China's Most Beautiful Book" jury. This is also the third year in a row that two of the "most beautiful books in China" have won awards, following 2016 and 2017. Collecting award-winning books is an effective way for family libraries to improve the quality of the collection of books, improve the structure of the collection of books and add value to their collection.

If the award-winning book is signed and printed by the author again, its value is even more unusual. For example, the frog, a famous novel by the famous Chinese writer Mo Yan, has won the Nobel Prize for literature.

\section{F. Traditional Isolated and Rare Books}

Due to historical reasons, rare and rare books are rare. Conditional family library collectors will focus on the strength of the target can reach "baby", when the time is ripe, will resolutely start. Generally speaking, for the vast majority of collectors of family library, it is difficult to realize the dream of collecting rare and good books. But, once the luck luck has had under the heart under the "baby", the collector certainly will regard as "family heirloom" treasures.

Except for the several directions of investment mentioned above, collectors of family library can also select official seals, autograph of the official seal, burr signature of the official seal, with the name of the recipient, QiongKuan, etc. Different forms make the collected books mean different meanings to collectors and have different economic values from the perspective of investment.

Many types of books with investment properties mentioned in this paper still exist in the "niche market", with limited circulation range. The consumption habits of the public are mainly ordinary books. However, under the influence of e-commerce environment, the market has gradually formed a number of Book Trading platforms, more representative of Confucius used book network, China Bookstore Berhong bookstore micro-store, Dangdang, and so on. The existence of these online trading platforms has promoted the transaction of books with investment properties mentioned in this paper, enhanced the market vitality, and directly affected the collection structure and collection quality of family libraries.

\section{PRoblems to Be PAID ATtention to IN THE INVESTMENT OF FAMILY LIBRARY}

After all, the family library is not a professional institution of investment. No matter what the basic function is, it is the collection, reading, borrowing, reading promotion, learning, etc. Therefore, family libraries can not look for all profitable opportunities of investment like enterprises, otherwise they will end up in reverse and lose their significance as a new type of library. In the operation of the family library, we should pay attention to the following problems.

\section{A. Excessive Pursuits of "Height" Lose the Essential Meaning of Family Library}

Firstly, family library is to meet the reading needs of family members. It usually shows certain characteristics in the collection structure and collection level according to the specific situation of family members (such as education level, work area, personal interest, age distribution, etc.). It may be that individual collectors of family library are keen on the influence of "celebrity" and try to collect their works, which results in the fact that the collection of family library is contrary to the real needs of family members and thus loses the essential significance of family library.

\section{B. Avoid the Mistake of "Commercialization"}

After all, the family library is not a business, so it cannot copy the business operation mode of the enterprise, and it cannot be evaluated by measuring whether the enterprise is profitable or not. Due to tight funding, it is possible that some collectors of family library choose to use their investment function to alleviate the pressure of shortage of funds, but this does not mean that the family library can be commercialized. Commercial household libraries have become for-profit enterprises, which is no different from bookstores in the market.

\section{Act According to Your Ability and Avoid Investment Risks}

The construction of family books not only needs the hardware input of equipment, decoration and so on, but also needs the input of software, time, energy and other aspects sometimes. What's more important is the huge investment in the library itself, which is hard for an ordinary family to bear. After all, the investment of family library is family behavior, and the ability to bear financial pressure and risk is limited after all. Collectors of family library should pay more attention to guard against market risks such as the prevention of commercial fraud, counterfeiting, and pirating books.

\section{CONCLUSION}

Family library plays an irreplaceable role in promoting reading activities of nations. A well-functioning family library can stimulate the interest of the whole community in reading. Family library has received people's attention in the 
Republic of China period, but the guidance has not been promoted and popularized today, people's understanding of family library still needs to be improved. If family library wants to achieve full development, it can not rely solely on its own function of investment. It needs the joint efforts of families, communities, governments and society to revitalize its life and play its unique role for social development.

\section{REFERENCES}

[1] Qiao Yang, Discussion on the construction of family library of community[J]. Library work and research, 2017 (1) : 94-98+120.

[2] Wang Hui, Discussion on the construction of family library of community [J]. Library research, 2016 (3) : 31-35.

[3] Qiao Yang, Construction and development of family library for community service [J]. Library work and research, 2017 (1) : 94$98+120$.

[4] Tang Yanqin, Gather social forces to build a family library [J]. Public library, 2015 (4) : 94-95.

[5] Ju Feng. Reserve a family "library" [N], China education newspaper, September 25, 2015 (6).

[6] Gu Danhua. The Model of Family Library [N] was introduced into the library in Qingpu district, China media business newspaper, May 19, 2015 (23).

[7] Chen Qun, Development of family library -- a case study of Yubei District construction of family library in Chongqing [C], Ma 'anshan, Anhui province: national federation of small and medium-sized public libraries, May 22, 2014:1476-1483.

[8] Wang Xiaoyi.Autograph book: once the title a hundred times[EB/OL],

http://finance.sina.com.cn/https://baike.so.com/doc/5819376-

6032190.htmlmoney/collection/gjsb/20100623/12558162920.shtml, on June 10, 2018.

[9] The autograph book club, a true story about the autograph book[EB/OL], http://bbs.tianya.cn/post-103-5666571https://baike.so.com/doc/5819376-6032190.html.shtml, on June 10, 2018 